\title{
How to Reach Effective Health Service Delivery?
}

\author{
Ann-Christine Andersson*
}

Jonkoping University, School of Health and Welfare, The Jonkoping Academy for Improvement of Health and Welfare, Sweden

*Corresponding author: Jonkoping University, School of Health and Welfare, The Jonkoping Academy for Improvement of Health and Welfare, Sweden, Tel: 0725241060; Email: Ann-Christine.Andersson@ju.se

Received date: August 9, 2017, Accepted date: August11, 2017, Published date: August 17, 2017

Copyright: ( 2017 Andersson AC. This is an open-access article distributed under the terms of the Creative Commons Attribution License, which permits unrestricted use, distribution, and reproduction in any medium, provided the original author and source are credited.

Keywords: Co-production; Collaboration; Health service; Patient processes

\section{Short Communication}

Health care today is persuaded to provide good service, not just cure ill patients. Patients will put demand on care providers and organisations to be effective and efficient, meeting their needs in a timely manner, being service minded and complaisant. Patients do not want to be seen as an illness or injury, they want to be seen as equals in need of service.

This means that health care need to get back to a more holistic view on what care is. It also includes more co-production [1], not only between care givers and their patient, but also between different caregivers across organizational boundaries. The biggest challenge to health care and social services today is how to produce the best and most effective and efficient care to all people in need. Public organizations are put under hard finical pressure, and new technology is good, but costly. Therefore, it would be even more important to cooperate in the future.

Patients would benefit from a more co-produced, co-constructive process throughout their health care journey [2]. Patient participation has shown led to safer care and most certain better availability. Lots of researchers has lately highlighted the importance to improve collaboration for and with patients [1-4], as the most necessary way to be able to deliver the care and service needed. The mostly sick, often elderly persons, in need of care mainly get care and services from many different care givers belonging to different organizations. To facilitate the patients' journey throughout the care process, health and service organizations must arrange smother pathways, and that need efforts and collaboration between all different parties, professionals, patients, leaders and system organizations [5].

Collaboration means intended care and service activities between at least two participants, and the patient, in order to facilitate the delivery of (health) care and services [6]. Most care givers have somewhat control over their own pathways and care processes, the flow inside their unit. But reports on adverse events shows that failures and mistakes arise in the gaps between organizations. In a report from The Swedish Health and Social Care Inspectorate (IVO) settled that different caregivers need to improve their collaboration and care processes, especially for elderly people [7]. The report also stated that although some efforts made, there still is a lot to do to improve collaboration and communication between healthcare, primary care and social care services. Structure changes and an elderly population will contribute to health and social care and welfare organizations need to be more integrated, which, in turn will put demands for collaboration on to these organizations [8].

J Gen Pract (Los Angel), an open access journal
The division of health care in several specialties and (sub) professions even more calls for better collaboration and interaction. The complexity require interaction between all concerned parties, patients, relatives, professions and different caregiving organizations to optimize service delivery. More collaboration hopefully brings us back to a more holistic approach, the patient as a person (comp. personcentered care), not as the Illness (the "leg" or "stomach"), which mainly as has been the focus in the divided production-based care of today. This is essential if we will go on improving our service delivery continuously and provide even better, more valuable care in the future [9]. In a longer perspective, collaboration and co-creation would not only improve care and social service, it would also be cost effective [6], since collaboration has shown decreased patients' readmissions to hospital, for example better handover, and readmissions are expensive [10]. An important tool to improve collaboration is communication [11]. In a study, aiming at improving service delivery to improve care between primary and secondary care, the first step was to improve the communication [12]. Communication skills helped to improve the relationship between general practitioners and specialized care givers.

During a recent research project, one relative told me about her family's journey when her husband got cancer, and finally died. She talked a lot of "the missing project coordinator", and illuminated their process along and between care givers and organizations. She felt that her primary duty was to coordinate the different care and service efforts. Only she knew all about her husband's care processes. One prominently episode was when the husband had come home for a weekend leave, at a Friday afternoon. The homecare personnel told them that they would need a bedpan, to be able to help, but they could not fix one. So, the relative phoned the district nurse, who told her that this was the occupational therapists duty. Calling an occupational therapist, she was told that a bedpan was an order goods, and it should take until Tuesday the week after to get one. So, what to do, a Friday afternoon? She is an energetic woman, so she called the nursing home in the nearby village, and they let her borrow a bedpan over the weekend. She drove there and got it herself. In this case, no collaboration at all was on forehand! The care and service organizations need to be better at helping patients to coordinate their needs, irrespective of who are "in charge".

Then how to deal with the collaboration gap that truly exists. One suggestion is to make interaction more efficient by providing a more global payment system for care across settings [13]. This will hopefully increase the willingness to try other pathways, if not the question about who is paying is on forehand. More emphasis must be put on coordination and care provision models, measure outcomes and use improvement methods to deal with better collaboration [6]. Another issue is the process of continuity of care across and between disciplinary and organizational boundaries [14]. Sometimes when care is fragmented and cross a lot of different systems, patients or relatives may be the only one knowing how the care actually was delivered [15]. 
Citation: Andersson AC (2017) How to Reach Effective Health Service Delivery?. J Gen Pract (Los Angel) 5: 320. doi: 10.4172/2329-9126.1000320

Page 2 of 2

Patients as part of collaborations can help to identify problems and mistakes within and between care givers and organizations. But the caregivers need to take lead on collaboration.

If caregivers better understand what is happened before and after the patients sees them, and if those caregivers also collaborate to facilitate the patient's journey, it will be better and safer for the patient, and thus, lead to better and more effective health service delivery.

\section{References}

1. Batalden M, Batalden P, Margolis P, Seid M, Armstrong G, et al. (2015) Coproduction of healthcare service. BMJ Qual saf 25: 509-517.

2. Josefsson K, Andersson AC (2017). The co-constructive processes in physiotherapy. Cogent Med 4: 1290308.

3. Robert G, Cornwell J, Locock L, PurushothamA, Sturmey G, et al. (2015) Patients and staff as codesigners of healthcare services. BMJ 350: g7714.

4. Bate P, Robert G (2006) Experienced-based design: From redesigning the system around the patient to co-desing services with the patient. Qual Saf Health Care 15: 307-310.

5. Batalden PB, Davidoff F (2007) What is "quality improvement" and how can it transform healthcare? Qual Saf Health Care 16: 2-3.

6. Moyers PA, Metzler CA (2014) Health Policy Perspectives Interprofessional Collaborative Practice in Care Coordination. American Journal of Occupational Therapy 68: 500-505.
7. IVO (The Health and social Care Inspectorate) (2015) Tillsynsrapport De viktigaste iakttagelserna inom tillsyn och tillstandsprvning verksamhetsaret 2014 (in Swedish).

8. Ponzer S, Faresjo T, Mogensen E (2009) Framtidens vard kraver interprofessionellt samarbete (In Swedish). Lakartidningen, 13: 929-931.

9. Robben S, Perry M, Van Nieuwenhuijzen L, Van Achterberg T, Rikkert $\mathrm{OM}$, et al. (2012) Impact of interprofessional education on collaboration attitudes, skills, and behavior among primary care professionals. Journal of Continuing Education in the Health Professions 32 :196-204.

10. Boutwell A, Hwu S (2009) Effective Interventions to Reduce Rehospitalizations: A Survey of the Published Evidence. Cambridge, MA: Institute for Healthcare Improvement.

11. Lifvergren S, Docherty P, Shani AB (2011) Toward a Sustainable Healthcare System: Transformation through Participation. Emerald insight 1: 99-125.

12. Fulup N, Allen P, Clarke A, Black N (2003) From health technology assessment to research on the organisation and delivery of health services: Adressing the balance. Health Policy 63: 155-165.

13. Lipsitz LA (2012) Understanding Health Care as a Complex System: The Foundation for Unintended Consequences. JAMA 308: 243-244.

14. Haggerty LJ, Reid JR, Freeman KG, Starfield HB, Adair EC, McKendry R (2003) Continuity of care: A multidisciplinary review 327: 1219-1221.

15. Gallagher TH, Mazor KM (2015) Taking complaints seriously: Using the patient safety lens. BMJ Qual Saf. 